\title{
UM ESTUDO DE CASO SOBRE IMPORTÂNCIA DO ENSINO MÉdio InTEGRAdo À EdUCAÇÃo PROFisSional PARA AS TRAJETÓRIAS DE VIDA DE EGRESSOS DO INSTITUTO Federal do Ceará/Campus Fortaleza
}

\author{
A CASE STUDY ON THE IMPORTANCE OF HIGH SCHOOL INTEGRATED TO \\ VOCATIONAL EDUCATION FOR THE LIFE TRAJECTORIES OF GRADUATES \\ OF THE FEDERAL INSTITUTE OF CEARÁ/ CAMPUS FORTALEZA
}

DOI: http://dx.doi.org/10.23926/RPD.2526-2149.2019.v4.n2.p755-774.id460

\section{Francisco das Chagas Torres de Oliveira Especialista em Gestão, Supervisão e Orientação Educacional (IESMA) fc.torres02@gmail.com}

\section{Samuel Brasileiro Filho \\ Doutor em Educação (UFC) samuelbrasileirofilho@gmail .$c 0 m$}

\begin{abstract}
Resumo: O presente trabalho constitui um recorte de uma pesquisa de mestrado realizada junto a egressos dos cursos técnicos em Mecânica Industrial, Química e Telecomunicações, ofertados pelo do Instituto Federal do Ceará - IFCE/Campus Fortaleza na modalidade do Ensino Médio Integrado à Educação Profissional e Tecnológica - EMI, os quais concluíram seus respectivos cursos no período compreendido entre os anos de 2016 e 2018. Compreende, portanto, um estudo de caso, que contou com a utilização de métodos e técnicas de natureza qualitativa para a coleta e tratamento dos dados obtidos a partir da realização de entrevistas semiestruturadas. Partindo das reflexões de autores como Moura, (2007); Bremer e Kuenzer (2012); Ramos (2014) Frigotto, Ciavatta e Ramos (2005); dentre outros, esta pesquisa objetivou evidenciar os sentidos que os egressos atribuem à formação recebida, bem como a importância que ela assume para a melhoria de suas condições materiais de existência e para sua autorrealização. Os resultados encontrados revelaram que os egressos, em sua ampla maioria, percebem a formação recebida como muito importante para o delineamento de suas trajetórias profissionais e acadêmicas, constituindo-se um "divisor de águas" para a transformação de suas condições materiais de vida e para o seu desenvolvimento humano.

Palavras-chave: Ensino integrado; Educação Profissional; Egressos; Formação Omnilateral.
\end{abstract}

\begin{abstract}
The present work presents the partial results of a master's degree research carried out with graduates of the technical courses in Industrial Mechanics, Chemistry and Telecommunications, offered by the Federal Institute of Ceará - IFCE / Fortaleza Campus in the modality of High School Integrated to Vocational and Technological Education - EMI, which completed their respective courses in the period between 2016 and 2018. It therefore includes a case study, using methods and techniques of a qualitative nature for the collection and processing of the data obtained semi-structured interviews. Starting from the reflections of authors like Moura, (2007); Bremer and Kuenzer (2012); Ramos (2014) Frigotto, Ciavatta and Ramos (2005); among others, this research aimed to highlight the meanings that the graduates attribute to the formation received, as well as the importance that she assumes for the improvement of their material conditions of existence and for their self-realization. The results revealed that the vast majority of the graduates perceive the training received as very important for the delineation of their professional and academic trajectories, constituting a "watershed" for the transformation of their material conditions of life and for their human development.
\end{abstract}

Keywords: Integrated teaching; Professional education; Graduates; Omnilateral Formation. 


\section{INTRODUÇÃO}

O presente artigo constitui um recorte de uma pesquisa de mestrado que encontra-se em fase de conclusão, cuja abordagem relaciona-se à temática do Ensino Médio Integrado à Educação Profissional e Tecnológica - EMI e se referencia nas discussões engendradas por pesquisadores brasileiros da relação educação e trabalho (MOURA, 2007; BREMER E KUENZER, 2012; RAMOS, 2014; FRIGOTTO, CIAVATTA E RAMOS, 2005; dentre outros), as quais contemplam em seu cerne a defesa da ideia de que o EMI seria o melhor modelo educativo de que se dispõe na realidade brasileira, ante o contexto de hegemonia do modo de produção capitalista, constituindo-se, portanto, como um caminho de travessia para uma educação omnilateral, concepção pedagógica marxiana mediante a qual é idealizada uma formação que contemple as várias dimensões da pessoa, não se restringindo a aspectos meramente profissionalizantes.

De antemão, cabe esclarecer que tal concepção não é consensual entre os estudiosos desse campo temático, sendo Paolo Nosella, estudioso das obras de Gramsci, um de seus principais opositores, o qual contrapõe-se à ideia de Ensino Médio Integrado à Educação Profissional como travessia para o alcance de uma educação omnilateral, por considerá-la uma abordagem reformista/conciliatória, isto é, de adequação à sociedade capitalista. O autor, destarte, posiciona-se a favor de uma abordagem revolucionária, a exemplo da proposta da escola média unitária de Gramsci, cuja viabilização está condicionada à superação do modelo societal vigente (NOSELLA, 2016).

Ressalvadas essas divergências teóricas e deixando claro que, neste artigo, assume-se o primeiro entendimento como referencial para a discussão que se propõe fazer, é importante situá-la no contexto mais amplo da problemática que a envolve: a conjuntura mundial de dominação do modo de produção capitalista, diante da qual se constata que o dualismo histórico do ensino tem sido uma constante, estando um de seus efeitos mais nocivos atrelado à oferta desigual de oportunidades formativas, na medida em que, a uma pequena parcela da população, a detentora dos meios de produção, é oferecida uma formação intelectual, preparadora dos futuros dirigentes da sociedade, ao passo que ao restante da sociedade, especificamente à classe trabalhadora, é concedida uma formação escolar limitada, focada em um ensino estritamente profissionalizante e direcionado, quase sempre, ao exercício do trabalho manual, acrítico, que destina os sujeitos a serem meros executores de tarefas de menor complexidade, negando-lhes o acesso aos conhecimentos que fundamentam suas atividades laborativas, bem como a uma 
formação mais ampla, que considere as dimensões política, ética, estética, afetiva, social, econômica de suas vidas.

A despeito desse cenário marcado pelas contradições históricas condicionadas pela lógica capitalista, faz-se mister considerar o fato de que o EMI passou a ser uma realidade possível nas práticas educativas brasileiras, assegurado por uma legislação (Lei de Diretrizes e Bases da Educação Nacional - LDBEN, Diretrizes Curriculares Nacionais, Pareceres, Resoluções, etc.) que foi se consolidando no desenrolar de uma história de avanços e retrocessos. Nesse sentido, entende-se que não se pode desprezar as valiosas contribuições que a referida forma de oferta de ensino tem proporcionado a milhares de jovens, dando-lhes condições de alcançar melhores patamares de vida, ainda que dentro dos limites impostos pela sociedade de mercado na qual convivem.

A partir de tais reflexões, a pesquisa buscou, por meio do contato direto com egressos dos cursos técnicos em Mecânica Industrial, Química e Telecomunicações, ofertados pelo Instituto Federal do Ceará - IFCE/Campus Fortaleza na modalidade do Ensino Médio Integrado à Educação Profissional e Tecnológica - EMI, levantar dados qualitativos sobre as suas trajetórias profissionais e formativas, visando evidenciar os sentidos que eles atribuem à formação recebida, bem como a importância dela para a melhoria de suas condições materiais de vida e para sua autorrealização.

Feitas essas considerações iniciais, a seguir, apresenta-se a sequência estrutural sob a qual o presente trabalho está organizado.

Na seção dois, faz-se uma breve apresentação das principais bases teóricas relacionadas diretamente à temática em questão, problematizando-se a dualidade estrutural que marca toda a história educacional brasileira, sobretudo no que concerne à relação entre ensino médio e ensino técnico. Por meio da terceira seção, discute-se acerca da possibilidade de EMI enquanto caminho alternativo de aproximação ao ideal marxiano de uma educação omnilateral e se faz algumas reflexões acerca da relevância institucional e social da pesquisa com egressos contemplados com o acesso à referida forma de oferta de ensino. Na seção quatro é feita a descrição dos métodos e procedimentos técnicos utilizados na coleta e tratamento dos dados levantados, explicitando-se as etapas do percurso que conduziu aos resultados encontrados, os quais são apresentados e discutidos na seção cinco. Por último, são feitas as considerações finais, a partir das quais são apontados os horizontes que a pesquisa possibilitou vislumbrar, enfatizando-se a importância da manutenção da oferta do EMI e a necessidade de se lutar pela expansão, com qualidade, de sua oferta em todo o território nacional. 


\title{
2 ASPECTOS HISTÓRICO-CONCEITUAIS DA RELAÇÃO EDUCAÇÃo E TRABALHO E O PROBLEMA DA DUALIDADE ESTRUTURAL EDUCACIONAL
}

A análise da relação trabalho e educação assume fundamental importância na obra de Karl Marx, dada a centralidade do trabalho para a vida em sociedade e sua intrínseca vinculação com todos os âmbitos da vida humana. Em Marx (2013) o trabalho é retratado como elemento constituinte e mediador da relação homem-natureza, possibilitando a satisfação das necessidades básicas dos seres humanos, processo mediante o qual o homem transforma a natureza e a si próprio, promovendo formas peculiares de sociabilidade:

\begin{abstract}
O trabalho é, antes de tudo, um processo entre o homem e a natureza, processo este em que o homem, por sua própria ação, medeia, regula e controla seu metabolismo com a natureza. [...] Agindo sobre a natureza externa e modificando-a por meio desse movimento, ele modifica, ao mesmo tempo, sua própria natureza. Ele desenvolve as potências que nela jazem latentes e submete o jogo de suas forças a seu próprio domínio (MARX, 2013, p. 326-327).
\end{abstract}

Essa concepção marxiana considera o trabalho a partir de uma perspectiva ontológica e, portanto, o entende como uma atividade dotada de intencionalidade, permitindo ao homem transpor os obstáculos naturais e intervir na natureza para adequá-la às suas necessidades básicas de sobrevivência, o que o distingue das demais espécies de animais existentes, cuja ação compreende uma resposta meramente adaptativa aos estímulos do ambiente natural circundante.

Partindo dessa compreensão, Dermeval Saviani (2007) lança um olhar analítico-crítico, relacionando a educação ao processo evolutivo das forças produtivas, ilustrando a presença do sentido ontológico do trabalho nas vivências humanas estabelecidas no contexto do modo de produção comunal, no qual a educação era naturalmente atrelada à atividade laborativa, uma vez que o processo educativo se dava durante a própria ação de trabalhar e, por meio desta, os homens educavam a si e aos demais e transmitiam aos seus descendentes os conhecimentos advindos de sua ação (trabalho) sobre a natureza. Portanto, não havia a separação entre trabalho e educação; ambos formavam uma unidade.

No entanto, o referido autor assevera que "a apropriação privada da terra, então o principal meio de produção, gerou a divisão dos homens em classes Configuram-se, em consequência, duas classes sociais fundamentais: a classe dos proprietários e a dos nãoproprietários" (SAVIANI, 2007, p. 155). A partir daí, ocorre a separação entre educação e trabalho, evento histórico que possibilitou aos detentores dos bens produtivos estabelecerem uma relação de dominação sobre aqueles que detinham a força de trabalho, promovendo a alienação do homem em relação ao produto do seu trabalho, bem como aos fundamentos e 
técnicas de sua produção, processo que foi se intensificando, nos diferentes modos de produção (escravista, feudal) até atingir seu estágio mais elevado com o advento e expansão em escala mundial do modo de produção capitalista, caracterizador da sociedade de mercado hodierna.

Ainda de acordo com o autor supracitado, é no contexto de expansão e consolidação desse modo de produção que, paradoxalmente, há uma reaproximação entre educação e trabalho, não alinhada à sua concepção ontológica, mas seguindo a determinação de uma lógica instrumental segundo a qual a preparação para o ingresso no mercado de trabalho se torna imprescindível, mormente ante o avanço das forças produtivas, potencializadas pelos avanços técnico-científicos fomentadores de um processo de complexificação que passa a exigir uma mão de obra altamente qualificada para reprodução do capital e de sua consequente forma de organização societal.

Considerando esses pressupostos teóricos e lançando um breve olhar para a história da educação brasileira, especialmente no que concerne à vinculação entre a Educação Profissional e a Educação Básica, torna-se evidente quão dual tem sido essa relação. Segundo, Moura (2007), a educação brasileira sempre foi marcada pela dualidade, estando situada dentro de uma dinâmica de confronto entre projetos sociais distintos, em meio ao qual a formação profissional sempre esteve atrelada às demandas do capital, com uma finalidade estritamente instrumental, cuja oferta se dirigiu, predominantemente, às classes populares. Já a educação geral, ou básica, como concebida na atualidade, sempre esteve associada aos interesses das elites e dos detentores dos meios de produção, viabilizando o acesso de seus filhos ao ensino superior, de modo a assegurar a hegemonia dessas classes.

Em consonância com o entendimento do autor supramencionado, Ramos (2014) faz uma relação direta entre a história do dualismo educacional do Brasil e a luta de classes no capitalismo, sendo aquela resultante desta. Ela afirma que a dualidade educacional está estreitamente vinculada à histórica luta de classes no contexto de hegemonia do capitalismo, o que justifica a permanente cisão entre uma educação destinada aos produtores da riqueza a partir do uso de sua força de trabalho e outra cuja destinação é dada às elites, isto é, àqueles que conduzem os rumos da sociedade, de acordo com seus interesses econômico-políticos.

Por sua vez, Romanelli (1986) corrobora o pensamento dos autores acima citados, manifestando igual entendimento de que a história da educação brasileira é marcada pela dualidade, na medida em que se constata que a estrutura educacional presente no Brasil, nas diferentes fases de sua história, delineou-se em conformidade com a dualidade presente em sua organização social, cujas raízes denunciam sua vinculação a um passado marcado pela 
escravidão. Tal constatação da autora conduz ao reconhecimento de que, historicamente, a escola assumiu papel determinante na manutenção dos privilégios de classes e no reforço das desigualdades, concedendo diferenciados níveis de acesso à cultura e ao saber, de modo a relegar às classes populares um ensino precário, ao mesmo tempo em que concedia às elites um ensino que lhes conferia prestígio social, mediante o acesso ao ensino superior.

A discussão centrada no problema da dualidade estrutural do ensino traz à tona uma outra questão importante presente nas reflexões de Kuenzer (2007, p.1162): o oferecimento de uma educação mais abrangente, não resolve o problema da dualidade estrutural do ensino, uma vez que ele é inerente à própria natureza do modo de capitalista de produção, que busca se reinventar periodicamente antes as crises que enfrenta, aprimorando suas estratégias de exploração com vistas à ampliação da margem de lucro, via estimulação do consumo desenfreado e insustentável. Nesse sentido, a autora destaca que a educação não é capaz de, por si só, promover a superação de tal dicotomia estrutural e histórica, de modo que a solução do problema passa pela superação do modo de produção capitalista e instauração de uma nova forma de organização econômica, social e política.

Por outro lado, a citada autora pontua que, embora a educação não detenha o poder de superação do dualismo estrutural do ensino, em meio as contradições decorrentes da própria essência do capitalismo e em consonância como o movimento dialético condutor da história, ao possibilitar à classe trabalhadora o acesso a níveis mais elevados de educação e qualificação, segundo seus interesses mercantis, o capital abre caminhos para a ação contra-hegemônica, já que "oferecer possibilidades de acesso em níveis cada vez mais ampliados a um número cada vez maior de trabalhadores tem conseqüências, uma vez que não há como controlar a energia liberada através da produção e circulação do conhecimento e da capacidade de análise crítica que este gera" (KUENZER, 2007, p. 1175).

A partir dessa importante ponderação, podem ser vislumbrados, portanto, caminhos alternativos para a confrontação do problema da dualidade aqui discutido, ainda que a realidade objetiva, nas esferas social, política e econômica, evidencie um quadro de acentuada exploração da classe trabalhadora e um horizonte de incertezas. Isto porque a história humana segue um fluxo dialético em meio ao qual ocorre uma contínua correlação de forças capaz de promover avanços ou retrocessos nas políticas socioeconômicas e, nessa perspectiva, não se pode considerar a educação apenas em sua face instrumental de alienação das massas e de reprodução dos interesses da classe dominante; ela também constitui um espaço de resistência e de formação crítica que tem uma grande contribuição para sedimentar as bases de uma sociedade 
melhor, a partir da oferta de uma formação de qualidade, gratuita, laica e socialmente comprometida (MOURA, 2007).

\section{O ENSINO MÉDIO INTEGRADO À EDUCAÇÃO PROFISSIONAL COMO A MELHOR EDUCAÇÃO DISPONÍVEL AOS FILHOS DA CLASSE TRABALHADORA BRASILEIRA}

Inicialmente, partindo de uma abordagem mais ampla, é importante destacar que o ideal filosófico marxiano de uma educação omnilateral compreende uma formação que considere o ser humano em sua integralidade, correspondendo, portanto, ao desenvolvimento do homem em todas as suas dimensões, de modo a superar o problema da dualidade instituída pela divisão social do trabalho, a qual remonta ao advento da propriedade privada, como já discutido no início deste trabalho. Segundo o filólogo Alighieri Manacorda, estudioso das obras de Marx:

A divisão do trabalho condiciona a divisão da sociedade em classes e, com ela, a divisão do homem; e como esta se torna verdadeiramente tal apenas quando se apresenta como divisão entre trabalho manual e trabalho mental, assim as duas dimensões do homem dividido, cada uma das quais unilateral, são essencialmente as do trabalhador manual, operário, e as do intelectual (MANACORDA, 2007, p. 77).

No entanto, como já pontuado na seção anterior, a partir das reflexões de Kuenzer (2007), o alcance de uma educação omnilateral está inevitavelmente condicionado à superação da divisão social de classes gerada pela divisão do trabalho, mediante uma ação popular revolucionária capaz de suplantar o modelo societal capitalista e instituir um novo modelo de sociedade que não se baseie na luta de classes e na exploração econômica, como destaca o filósofo marxista Louis Althusser (1918-1990), ao fazer sua “Advertência aos leitores do Livro I d'O capital”, comentando aspectos-chave obra de Marx: “[...] a classe operária não pode esperar nenhum benefício do desenvolvimento da produtividade moderna antes de derrubar o capitalismo e tomar o poder de Estado através de uma revolução socialista" (MARX, 2013, p. 69).

Por outro lado, há que se destacar que a proposição de uma via intermediária educacional não abdica dos ideais revolucionários defendidos por Marx e seus seguidores, pois, como como pondera (Moura, 2007), é preciso reconhecer as condições objetivas da realidade hodierna, especialmente a brasileira, ante a qual não se vislumbra, a curto e médio prazo, uma mudança para uma lógica societal diferente da atual, isenta das condicionantes exercidas pelo modo de produção capitalista.

Seguindo esse viés de entendimento, acredita-se ser possível pensar em uma educação compromissada com a formação dos jovens em diferentes aspectos: intelectuais, ético-morais, estéticos, políticos e profissionais, dando-lhes, assim, condições de analisar criticamente a 
sociedade na qual estão inseridos, de terem autonomia para trilhar outros percursos formativos para além da educação básica e profissional, além de despertá-los para o engajamento com as causas políticas e sociais em prol da transformação contínua da realidade circundante, sem deixar de rumar ao ideal maior de superação do modelo societal orientado pela lógica capitalista.

Nessa perspectiva, alguns estudiosos da relação entre educação e trabalho, a exemplo de Moura (2007); Bremer e Kuenzer (2012), Frigotto, Ciavatta e Ramos (2005), dentre outros, advogam ser o Ensino Médio Integrado à Educação Profissional uma proposta formativa alternativa a ser promovida e defendida, tendo em vista ser essa a melhor educação a ser oferecida aos jovens brasileiros, dentro das circunstâncias concretas da conjuntura social, política e econômica que se impõem. Tal compreensão foi sendo construída em meio aos avanços e retrocessos registrados no desenvolvimento da história da legislação educacional brasileira, como resultado do embate das forças ideológicas progressistas contra as conservadoras, estas vinculadas ao poder político-econômico dominante; ela, destarte, está assentada no seguinte pressuposto:

[...] ensino médio integrado é aquele possível e necessário em uma realidade conjunturalmente desfavorável- em que os filhos dos trabalhadores precisam obter uma profissão ainda no nível médio, não podendo adiar este projeto para o nível superior de ensino- mas que potencialize mudanças para, superando-se essa conjuntura, constituir-se em uma educação que contenha elementos de uma sociedade justa (FRIGOTTO, CIAVATTA, RAMOS, 2005, p. 44).

Em termos conceituais, a proposta de integração do ensino médio à educação profissional é subsidiada, filosoficamente, pela compreensão de que ela reflete, sobretudo, uma concepção de formação humana, a partir da qual os processos formativos devem considerar a integralidade, isto é, as diferentes dimensões do ser humano, as quais envolvem o trabalho, a ciência e a cultura (Ramos, 2014). Nas palavras da autora, eis o significado de cada uma dessas dimensões:

O trabalho compreendido como realização humana inerente ao ser (sentido ontológico) e como prática econômica (sentido histórico associado ao modo de produção); a ciência compreendida como os conhecimentos produzidos pela humanidade que possibilita o contraditório avanço das forças produtivas; e a cultura, que corresponde aos valores éticos e estéticos que orientam as normas de conduta de uma sociedade (RAMOS, 2014, 87)

No que concerne à viabilização da oferta dessa forma articulada de ensino, há que se destacar que o Brasil possui uma legislação educacional (LDBEN, diretrizes e resoluções do MEC/CNE) que permite, paradoxalmente, a coexistência do ensino integrado e não integrado, ainda que se saiba que a implementação do primeiro não seja do interesse da maior parte dos 
governantes e dos organismos financeiros internacionais que interferem nas decisões políticas e econômicas do País (FMI - O Fundo Monetário Internacional e Banco Mundial, sobretudo), o que não tem impedido que o mesmo continue a ser ofertado regularmente pelas instituições de ensino vinculadas à Rede Federal de Educação Profissional, Científica e Tecnológica RFEPCT (apesar da falta de investimentos e de formação docente adequados e tantas outras dificuldades que essas instituições enfrentam).

Um exemplo dessa possibilidade é representado pelo Decreto 5.154/2004, que tornou possível novamente a integração do ensino médio ao ensino profissionalizante, mediante a revogação do Decreto 2.208/97, instituído durante o governo de Fernando Henrique Cardoso, que não permitia tal articulação. Segundo Ramos (2014, p. 81), o primeiro decreto buscou "restabelecer os princípios norteadores de uma política de educação profissional articulada com a educação básica, tanto como um direito das pessoas quanto como uma necessidade do país". Em síntese, de acordo com a autora, com a publicação do decreto em questão, em 2004, buscouse pensar a organização da educação profissional sob uma ótica sistêmica, envolvendo a ação colaborativa de estados e municípios, os quais deveriam assumir papéis estratégicos no processo de viabilização dessa forma de oferta de ensino.

Consoante a essa compreensão, Bremer e Kuenzer (2012), destacam que por meio da instituição do referido decreto "reafirma-se a importância dessa legislação ao trazer para o cenário atual os princípios fundamentados em Marx, Engels e Gramsci para a formação omnilateral dos sujeitos" (BREMER E KUENZER, 2012, p. 7), reconhecendo o seu papel para uma reaproximação com o ideal marxiano do qual se tem tratado neste trabalho.

Diante das considerações teóricas que se fez até aqui, fica evidente que, embora atualmente se disponha de algum amparo e "incentivo" legal para a oferta do EMI, há diversas condicionantes de ordem política e econômica, como alertam Moura e Lima Filho (2017), que interferem na implementação dessa proposta formativa, sendo uma das mais preocupantes a seguinte: o recrudescimento das políticas neoliberais orientadoras das decisões do Governo Federal brasileiro atual, dentre as quais se destacam a aprovação pelo Congresso Nacional da Emenda Constitucional 95/2016, que impõe o congelamento dos gastos dos investimentos públicos por 20 anos, e a Reforma do Ensino Médio, cujos mecanismos regulatórios estão expressos na Lei 13.415/2017,o que constitui uma grande ameaça à manutenção dessa forma de oferta de ensino.

Tal cenário ameaçador lança sobre as instituições que compõem a Rede Federal de Educação Profissional, Científica e Tecnológica (RFEPCT), um dos principais lócus de oferta 
do EMI, bem como sobre todos os defensores de uma educação integral, pública e de qualidade, o reincidente desafio de se lutar, não somente, para que sua oferta seja mantida, mas para que, sobretudo, esta continue o seu processo de expansão, tendo em vista a existência de um público potencial gigantesco a ser alcançado.

Nesse sentido, acredita-se que a pesquisa com egressos sejam uma oportuna forma de contribuir com essa luta, na medida em eles sejam considerados como importantes divulgadores e defensores do ensino de qualidade e transformador que tiveram a oportunidade de receber. Corroborando esse entendimento, o relatório da Pesquisa Nacional de Egressos dos cursos técnicos de nível médio da RFEPCT, desenvolvida pela SETEC/MEC, em 2009, faz a seguinte consideração sobre a importância da escuta dos egressos pelas instituições formadoras:

\begin{abstract}
Neste sentido, os egressos das instituições de ensino se revelam como atores potencializadores de articulação com a sociedade, fonte de informações que possibilita retratar a forma como a sociedade em geral, percebe e avalia estas instituições, tanto do ponto de vista do processo educacional, como também do nível de interação que se concretiza. Portanto, é fundamental que as instituições de ensino estabeleçam um canal de comunicação com este segmento (BRASIL, 2009, p.14).
\end{abstract}

Sob esse prisma, a pesquisa com egressos da referida Rede oportuniza uma visão ampliada quanto às repercussões de sua atuação na vida daqueles que por ela são acolhidos, viabilizando, assim, uma maior legitimação do importante trabalho que presta à sociedade brasileira. Neste particular, é igualmente oportuno destacar a atuação profícua dos Institutos Federais de Educação, Ciência e Tecnologia, os quais, na visão de Pacheco (2011, p. 17), constituem "um projeto progressista que entende a educação como compromisso de transformação e de enriquecimento de conhecimentos objetivos capazes de modificar a vida social e de atribuir-lhe maior sentido e alcance no conjunto da experiência humana" (PACHECO, 2011, p. 17).

Por fim, considera-se que a escuta de egressos do EMI é uma oportunidade de pôr em evidência a efetividade do ensino disponibilizado sob essa forma de ensino, na medida em que a manifestação das percepções desses sujeitos sobre suas vivências formativas, interrelacionadas às suas experiências profissionais e sociais posteriores à conclusão do curso possam servir de elementos de validação social do ensino que lhes foi dispensado.

\title{
4 Metodologia
}

Como já se destacou introdutoriamente, por meio deste artigo, são apresentados resultados parciais de uma pesquisa de mestrado desenvolvida junto a egressos dos cursos técnicos em Mecânica Industrial, Química e Telecomunicações/Campus de Fortaleza do 
Instituto Federal do Ceará - IFCE, a qual configurou-se como um estudo de caso, isto é, uma "pesquisa que se concentra no estudo de um caso particular, considerado representativo de um conjunto de casos análogos, por ele significativamente representativo" (SEVERINO, 2007, P. 121) ou ainda, um "estudo profundo e exaustivo de um ou de poucos objetos, de maneira a permitir o seu conhecimento amplo e detalhado" (GIL, 2008, p. 57).

No que concerne à observância aos requisitos legais e éticos, cabe destacar que a referida pesquisa foi submetida à apreciação do Comitê de Ética do IFCE, no dia 28/05/2018, por meio do protocolo de registro na Plataforma Brasil $n^{\circ} 1145877$, tendo o parecer de sua aprovação sido emitido em 21/08/2018, sob o n ${ }^{\circ} 2.833 .748$.

O recorte da pesquisa que este artigo abrange teve uma abordagem qualitativa, levandose em conta que os propósitos investigativos a ela subjacentes compreenderam a coleta, análise e interpretação de dados não quantificáveis. Tal escolha encontra fundamento na compreensão que manifesta Minayo (2011, p. 21), ao conceituar e descrever a pesquisa qualitativa, asseverando que "ela trabalha com o universo dos significados, dos motivos, das aspirações, das crenças, dos valores e das atitudes", estando diretamente relacionada ao universo das relações, das representações, da intencionalidade, da subjetividade.

Assim, norteando-se por tais pressupostos metodológicos, nos dias 21 e 22 de outubro de 2018, na Sala de Videoconferência do IFCE/Campus Fortaleza, foram realizadas entrevistas semiestruturadas com seis egressos dos anos de 2016, 2017 e 2018, sendo cada um dos cursos supracitados representados por dois depoentes, os quais foram escolhidos na primeira etapa da pesquisa, a partir da aplicação de um questionário online, cujo envio se deu por meio de e-mail e do aplicativo de mensagens instantâneas "WhatsApp", utilizando-se os contatos fornecidos pela Coordenadoria de Controle Acadêmico (CCA), do IFCE/Campus Fortaleza.

As entrevistas foram transcritas com o auxílio do software de reconhecimento de voz e de transcrição instantânea Speechlogger ${ }^{1}$, tendo a interpretação dos dados sido mediada pela Análise de Conteúdo (BARDIN, 2016; FRANCO, 2008; GOMES, 2011). Tal método analítico, de acordo com Bardin (2016, p. 125-131), tem seu processo básico estruturado em três etapas principais: 1. Pré-análise, por meio da qual procede-se à leitura flutuante do material bruto coletado e é selecionado aquilo que será efetivamente analisado, isto é, o corpus entendido pela

\footnotetext{
${ }^{1}$ Constitui um software gratuito de reconhecimento de voz e de tradução instantânea de voz da web. Ele executa as tecnologias do Google de fala para texto para melhores resultados. Disponível em: <https://speechlogger.appspot.com/pt/>. Acesso em: 4 set. 2019.
} 
referida autora como "o conjunto de documentos tidos em conta para serem submetidos aos procedimentos analíticos"; 2. Exploração do material, pela qual se busca codificar, classificar e categorizar o material escolhido na etapa anterior; 3 . Tratamento dos resultados, ocasião na qual o analista/pesquisador pode fazer inferências e interpretações acerca do conteúdo analisado.

Durante o processo de transcrição das entrevistas, optou-se por realizar a identificação dos depoentes segundo a seguinte codificação: $\mathrm{E}=$ egresso + número referente à ordem da entrevista transcrita + as iniciais do nome e do último sobrenome do egresso, conforme consta no Quadro 1, por meio do qual se faz uma breve caracterização dos entrevistados:

Quadro 1 - Caracterização dos participantes da pesquisa

\begin{tabular}{|c|l|c|c|c|}
\hline Identificação & Idade & $\begin{array}{c}\text { Estado } \\
\text { Civil }\end{array}$ & $\begin{array}{c}\text { Curso/Ano De } \\
\text { Conclusão } \\
\text { Técnico Integrado em } \\
\text { Mecânica (2018.1) }\end{array}$ & $\begin{array}{c}\text { Estudante de Engenharia } \\
\text { Mecânica }\end{array}$ \\
\hline E1AJ & 19 anos & Solteiro & Solteira & $\begin{array}{c}\text { Estudante de Engenharia } \\
\text { Técnico Integrado em } \\
\text { Mecânica (2018.1) } \\
\text { Aprendiz em uma CIA } \\
\text { de bebidas }\end{array}$ \\
\hline E3NS & 19 anos & Solteira & $\begin{array}{c}\text { Técnico Integrado em } \\
\text { Telecomunicações } \\
\text { (2017) }\end{array}$ & Estudante de Jornalismo \\
\hline E4RL & 18 anos & Solteira & $\begin{array}{c}\text { Técnico Integrado em } \\
\text { Telecomunicações } \\
\text { (2017) }\end{array}$ & $\begin{array}{c}\text { Supervisora de suporte e } \\
\text { estudante de Engenharia } \\
\text { de Telecomunicações }\end{array}$ \\
\hline E5TN & 21 anos & Solteira & $\begin{array}{c}\text { Técnico Integrado em } \\
\text { Química (2016) }\end{array}$ & $\begin{array}{c}\text { Estudante de Engenharia } \\
\text { Química e estagiária em } \\
\text { uma empresa de } \\
\text { pesquisa agropecuária }\end{array}$ \\
\hline E6TV & 20 anos & Solteiro & $\begin{array}{c}\text { Técnico Integrado em } \\
\text { Química - (2018.1) }\end{array}$ & $\begin{array}{c}\text { Auxiliar de laboratório } \\
\text { em uma fábrica }\end{array}$ \\
\hline
\end{tabular}

Fonte: Elaborado pelo autor.

Finalmente, a partir da articulação entre os dados coletados e o referencial teórico estudado, foram definidas duas categorias de análise dos depoimentos concedidos, cujas discussões relacionadas serão apresentadas na seção seguinte, tendo em vista o objetivo deste trabalho em evidenciar os sentidos que os depoentes atribuem à formação recebida, bem como a importância dela para a melhoria de suas condições materiais de vida e para sua autorrealização. 


\section{RESUltados E DISCUSSÃO}

A seguir, descrever-se-ão as duas categorias de análise que emergiram das articulações que se buscou fazer entre o conteúdo dos depoimentos concedidos pelos egressos supra caracterizados e o referencial teórico estudado, sobretudo no que concerne à concepção defendida na presente produção científica, a partir da qual o Ensino Médio Integrado à Educação Profissional (EMI) é tomado como caminho alternativo de luta pela oferta de uma formação integral aos jovens brasileiros, levando em consideração as suas dimensões física, afetiva, ética, estética, política e social, em contraposição a uma formação instrumental com vistas ao mero atendimento de demandas mercadológicas (Moura, 2007; Ramos, 2014).

\subsection{CATEgORIA 01 - EMI E A PROMOÇÃo de FORMAÇÃo hUMANA}

Os conteúdos abrangidos por esta categoria estabelecem relação de aproximação com uma das dimensões centrais da concepção de uma formação omnilateral, a qual compreende necessidades formativas relativas à disseminação de valores como liberdade, autonomia e respeito às diferenças, com vistas ao fomento de um sadio convívio humano. Nessa perspectiva, é possível estabelecer diálogo com o seguinte entendimento de Marise Ramos:

[...] uma educação integrada contribui para a formação de sujeitos autônomos que possam compreender-se no mundo e dessa forma, nele atuar, por meio do trabalho, transformando a natureza em função das necessidades coletivas da humanidade e, ao mesmo tempo, cuidar de sua preservação face às necessidades dos demais seres humanos e das gerações futuras. (RAMOS, 2014, p. 93)

A essa compreensão pode-se ainda associar à de Paolo Nosella (2007), quando enfatiza a necessidade de a escola, inspirada nos ideais educacionais gramscianos, promover no educando o fomento ao exercício da liberdade, com responsabilidade, ainda que não se desvincule de propostas de ensino pautadas no rigor e na disciplina. Nesse sentido, assevera o autor, "o educador não pode jamais perder de vista o horizonte de liberdade plena, concreta e imanente como objetivo fundamental da educação.” (NOSELLA, 2007, p.150).

Consoantes a ambas as concepções supracitadas estão as falas dos egressos (E2KS, E3NS, E5TN e E6TV), cujo teor explicitam suas percepções acerca de um ensino promotor de autonomia e liberdade:

Quando eu entrei aqui, eu tinha apenas 14 anos, então, eu amadureci aqui dentro, porque é bem diferente de outras escolas que tem reunião de pais; os pais estão te acompanhando... Aqui não! É você e é você. Então, isso fez com que eu crescesse e amadurecesse aqui dentro mesmo. E eu vejo que isso me ajudou bastante, porque hoje eu resolvo tudo por mim, sozinha, e isso no mercado de trabalho é muito importante. (E2KS) 
[...] A minha maior felicidade foi, realmente, conseguir ser independente como eu sou hoje. Hoje em dia eu vou muito mais atrás de tudo na minha vida, seja a parte de saúde, resolver algum problema, resolver algum trabalho, alguma pendência... sempre por conta dessa liberdade que o IFCE me trouxe, que esse momento da minha vida me trouxe. Então, essa liberdade é o maior ponto que eu tive aqui no IFCE. (E3NS)

Como eu estudei numa escola onde tudo era muito mais rígido, então, aqui eles dão muito liberdade para você, tipo: você pode ir à aula ou não; o professor não tá ali segurando você... então, você ver de tudo: pessoas andando pelos corredores, você tem muita liberdade aqui. Eu acho que isso trouxe para mim muito uma ideia de responsabilidade, trouxe para mim um amadurecimento nesse ponto (E5TN)

Como eu vim da rede particular e o colégio de onde eu vim era bastante rígido nas regras, era tudo bem fixado; você não tinha muitas possibilidades de interação dentro do ambiente escolar: era da entrada para dentro da sala de aula e da sala para fora. [...] Assim, foi um baque; eu vim de uma estrutura rígida para uma estrutura tão flexível como a do IFCE, que dá tanta liberdade para os seus alunos. (E6TV)

Some-se a esses relatos, as percepções de dois egressos, em cujas falas ficou evidenciado que, durante seu processo formativo no IFCE/Campus Fortaleza, promoveu-se a obtenção de aprendizagens relacionadas ao respeito às diferenças e ao consequente preparo para uma saudável convivência humana. Nesse sentido, assim se expressa o egresso E6TV: "com relação à cultura, foi a cultura que eu adquiri aqui, vivendo este espaço tão aberto, de tão livre expressão: pessoas de todos os gêneros, todas as escolhas sexuais, com as suas liberdades aqui dentro... aprendi a respeitar mais as pessoas". Por sua vez, a egressa E3NS sublinha em seu relato a heterogeneidade de sua turma, destacando os diferentes perfis de pessoas que a compunham: "[...] tinha pessoas de cada tipo de pensamento; tinha pessoas de jeitos, de peculiaridades, de modo que cada uma pessoa era especial. [...] Mas aí a gente ia aprendendo, também, a lidar com a diferença do outro". Ambas as falas, portanto, apresentam elementos importantes indicadores de uma formação para uma vivência harmoniosa em sociedade, considerando o outro em sua individualidade e em sua dignidade de ser humano, isto é, evidencia-se a influência humanizadora da formação recebida pelos egressos.

\subsection{CATEgoria 02 - EMI E SUA IMPORTÂNCIA PARA PROMOÇÃo de MELHORES CONDIÇÕES SOCIOECONÔMICAS DE VIDA}

Esta categoria de análise engloba falas dos egressos que evidenciam a importância da formação recebida para o seu desenvolvimento integral e, em consonância com o referencial teórico discutido, sublinha o papel do EMI no contexto contraditório da realidade políticoeconômica hodierna do Brasil. Nesse sentido, retoma-se o posicionamento de Ramos (2014, p. 84), quando defende "uma concepção de formação humana, com base na integração de todas as dimensões da vida no processo educativo, visando à formação omnilateral dos sujeitos" e sinaliza o EMI como caminho a ser trilhado nessa direção. 
Evidentemente, ainda que se tenha consciência de que a proposta EMI não pode ser romantizada, entende-se também que essa é uma enorme conquista social proveniente das muitas lutas históricas que se têm travado em prol de uma educação emancipatória e progressista e que, portanto, precisa ser defendida das tentativas de desmonte decorrentes dos ataques denunciados por Moura e Lima Filho (2017), como refletido na seção 3 desta produção acadêmica. Ademais, é oportuno salientar que tal proposta formativa, segundo Moura (2007), é tida como uma solução transitória que considera as especificidades da realidade do Brasil, as contradições da sua legislação educacional, mormente em um momento como o atual, marcado por grandes incertezas em relação aos rumos que tomarão as políticas de educação do País. Assim,

[...] é preciso ter claro que essa gradativa expansão da oferta de ensino médio integrado à educação profissional técnica de nível médio não visa, em princípio, a sua universalização. Entretanto, objetiva sedimentar as bases, plantar as sementes de uma futura educação politécnica ou tecnológica, essa sim deverá ter caráter universal (além de ser pública, gratuita, laica e de qualidade), mas só poderá ser implantada quando as condições objetivas da sociedade brasileira assim o permitir. Enquanto isso, a prioridade deverá ser consolidar essa oferta que conjuga ensino médio e educação profissional na perspectiva da formação integral dos sujeitos que a ela tiverem acesso. (MOURA, 2007, p. 28)

A partir do diálogo estabelecido entre tais reflexões teóricas e os depoimentos dos egressos entrevistados, pôde-se constatar que todos eles atribuem elevado grau de importância à formação advinda dos seus respectivos cursos técnicos integrados, tendo a análise de suas falas permitido a apreensão de alguns sentidos atribuídos por tais sujeitos à formação recebida. $\mathrm{O}$ primeiro deles é encontrado em falas que atrelam o ensino oportunizado à promoção de desenvolvimento humano, a exemplo da seguinte: “O IFCE me mudou desde o dia que eu cheguei: como pessoa, como colega, como filho; em todos os aspectos da minha vida eu me tornei diferente" (E1AJ). Tal percepção também está contida nos depoimentos de outros egressos:

O IFCE, de certa forma, ele foi um divisor de águas na minha vida. Quando eu entrei aqui, aos 13 a 14 anos, eu era apenas uma menina [...] E a partir do momento que eu fui me desenvolvendo como aluna, como pessoa, eu fui desenvolvendo a felicidade em quebrar obstáculos: aquela menina que era boa em humanas se tornou boa em matemática, se tornou boa em comunicação, se tornou boa em informática, se tornou boa em relacionamentos com os outros, se tornou boa em conhecer um mundo novo, em ter empatia por alguém. O IFCE trouxe esse meu lado humano. (E3NS)

Em três anos e meio, eu virei outra pessoa; uma pessoa madura. Em comparação com as pessoas da minha idade que estão saindo do ensino médio, é uma pessoa totalmente diferente; é uma pessoa que tem uma maturidade (E4RN)

[...] eu aconselho todo mundo a se formar aqui, porque, realmente, o IF é uma instituição que forma você como pessoa, como profissional, traz valores éticos... 
forma você para ser um ser humano melhor, não só um profissional. Eu acho que traz muito dessa humanização da pessoa. (E5TN)

Um segundo sentido que aparece nos depoimentos situa-se na compreensão do curso concluído como "um divisor de águas", expressão que aparece, tanto na fala transcrita da egressa E3NS (acima citada), quanto na do egresso E6TV, quando este faz o seguinte comentário sobre o curso técnico integrado: "é um divisor de águas para quem faz: você é alguém antes de entrar no IFCE, e você é outra pessoa depois que você sai, tanto profissionalmente quanto pessoalmente, culturalmente... Você nunca sai daqui do jeito que você entra". Reforçando essa percepção, segue o trecho do depoimento de outra entrevistada:

O IF foi, com certeza, um divisor de águas entre o antes e o depois. E foi ótimo! Eu realmente achava que ia trazer para mim (e trouxe!) o que eu imaginava, que foi o encaminhamento acadêmico e profissional, também porque o curso que eu fiz aqui me fez escolher a profissão que eu pretendo ser. (E5TN)

Ainda que de forma indireta, nota-se que esse sentido também é expressado pela egressa E4RN, quando ela diz: "Eu não seria essa pessoa que agora trabalha, que ganha um bom salário, que vai conseguir fazer uma graduação para a família, se não tivesse entrado para fazer o curso técnico integrado em Telecomunicações, em 2014." Portanto, verifica-se claramente que os egressos tratam o curso concluído como um marco nas suas vidas, sem o qual eles entendem que não teriam tido acesso às oportunidades acadêmicas e profissionais que lhes foram apresentadas, tampouco às transformações pessoais que julgam ter vivenciado.

Finalmente, o terceiro sentido evidenciado nos relatos dos depoentes constitui um desdobramento do segundo e diz respeito ao papel do curso para o delineamento de suas trajetórias de vida profissional/acadêmica. Como exemplos podem ser citados os seguintes:

[...] O IFCE trouxe esse meu lado humano; ele trouxe um lado mais desenvolvido, mais centrado e mais calmo. Então, ele trouxe essa construção de um novo "eu", que não conhecia, mas que eu sou muito grata pela realização e pela forma que ele me tornou; pela jornalista que eu serei e pela pessoa honrada, grata, completamente grata, por tudo o que o IFCE trouxe para minha vida. (E3NS)

Quando eu me formei, eu fiz o discurso dizendo que eu tenho que dar todas os agradecimentos ao IFCE, porque aqui eu conheci, realmente, a paixão da minha vida. Telecomunicações eu não tinha a mínima noção do que era e, atualmente, ela guia a minha vida: eu trabalho com isso, meu namorado trabalha com isso, eu conheci ele por isso, eu estudo isso...Sem Telecomunicações eu não sei o que eu seria. E sem o IFCE, eu não teria conhecido Telecomunicações. (E4RN)

A importância desse curso na minha vida foi crucial! Esse curso, como eu disse, ele me abriu horizontes; ele abriu a minha mente. [...] ele é um curso que lhe abre portas... para mim ele foi um divisor de águas. Eu vejo que, talvez, se eu não tivesse feito ele, eu estaria ainda fazendo um preparatório, tentando entrar em uma universidade e em busca de um emprego, ainda que seria bem complicado de conseguir só com ensino médio. (E6TV) 
Pelos relatos destacados, evidencia-se que, para os depoentes, seus respectivos cursos técnicos integrados concluídos no IFCE possibilitaram-lhe traçar percursos profissionais e acadêmicos que lhes conferem orgulho e satisfação. Também é notório o sentimento de gratidão que eles nutrem pela Instituição que os formou e, nesse particular, considerando o fato de o Instituto Federal do Ceará integrar a Rede Federal de Educação Profissional, Científica e Tecnológica (RFEPCT), e que a sua defesa é uma demanda urgente, diante dos avanços da "onda" neoliberal que avança sobre as políticas educacionais do País, compreende-se que os depoimentos concedidos pelos egressos, de modo geral, contribuem para isso, uma vez que, empiricamente, traduzem as reflexões de Pacheco (2011, p. 17) sobre o projeto progressista de sociedade que a referida Rede sustenta, entendendo a educação "como compromisso de transformação e de enriquecimento de conhecimentos objetivos capazes de modificar a vida social e de atribuir-lhe maior sentido e alcance no conjunto da experiência humana", o que encontra ressonância na fala da egressa E4RN: "Eu sou a primeira pessoa da família a fazer uma graduação, graças ao Instituto. Então, a minha família vai realmente mudar socialmente, graças ao Instituto Federal. Então eu tenho só agradecer.”

\section{CONSIDERAÇÕES FINAIS}

Tomando como referência o objetivo central da pesquisa que, parcialmente, o presente artigo relata, qual seja: "evidenciar os sentidos que os egressos entrevistados atribuem à formação recebida, bem como a importância dela para a melhoria de suas condições materiais de vida e para sua autorrealização", considera-se que este foi alcançado, tendo em vista que a análise do conteúdo dos depoimentos concedidos revelou que tais sujeitos consideram como muito relevante a formação recebida nos seus respectivos cursos técnicos integrados, destacando contribuições dela para a transformação de suas vidas em várias perspectivas: pessoal, social, acadêmica e profissional, bem como para o desenvolvimento de autonomia, liberdade, responsabilidade e respeito à alteridade.

Tais relatos também mostram que a formação que o EMI promove, ainda que não supere a dualidade educacional estrutural que aqui se problematizou, ameniza seus efeitos nefastos nas vidas dos jovens aos quais é oportunizado o acesso a essa forma de oferta de ensino, isto porque ela não se restringe a propósitos de profissionalização que visam, exclusivamente, ao atendimento de demandas mercadológicas, mas possibilita, sobretudo, condições de eles seguirem, inclusive, outros percursos formativos, no âmbito da educação superior, configurada como um espaço elitista, durante grande parte da história da educação brasileira. 
Destarte, chega-se ao final desta produção acadêmica com a convicção de que o EMI é uma importante alternativa de formação aos jovens oriundos da classe trabalhadora, na medida em que os seus resultados evidenciaram elementos de aproximação dessa forma de oferta de ensino com o ideal marxiano de uma educação omnilateral, embora se tenha consciência de que este só poderá ser plenamente alcançado mediante a instauração de um outro projeto societal que supere o que está em vigor, estreitamente atrelado à lógica do modo de produção capitalista.

Ademais, há que se enfatizar que o EMI é uma realidade ainda possível, a despeito da contraditória e desafiadora conjuntura social, política e econômica em meio a qual ele se materializa e, por essa razão, compreende-se que o momento atual exige de todos (pensadores envolvidos com tal temática, instituições de ensino e suas diferentes instâncias representativas, políticos, sociedade civil e todos os que estejam alinhados aos ideais sociais progressistas), um forte e expressivo engajamento com essa agenda, a fim de assegurar a manutenção dessa e de tantas outras conquistas históricas, obtidas por meio de inúmeras batalhas sociais e políticas. Do contrário, corre-se o grande risco de que elas sejam suplantadas pelo projeto de desmonte da coisa pública que vem se deslindando veloz e assustadoramente no País.

\section{REFERÊNCIAS}

BARDIN, Laurence. Análise de Conteúdo. Tradução de Luís Antero Reto. São Paulo: Edições 70, 2016.

BREMER, Maria Aparecida de Souza; KUENZER, Acácia Zeneida. Ensino médio integrado: uma história de contradições. In: SEMINÁRIO DE PESQUISA EM EDUCAÇÃO DA REGIÃO SUL; ANPED SUL, 9., 2012, Caxias do Sul. Disponível em: http://www.ucs.br/etc/conferencias/index.php/anpedsul/9anpedsul/paper/viewFile/2217/208. Acesso em: 05 maio. 2019.

BRASIL, MEC/Secretaria de Educação Profissional e Tecnológica. Pesquisa Nacional de Egressos dos Cursos Técnicos da Rede Federal de Educação Profissional e Tecnológica (2003-2007). Brasília, 2009. Disponível em:

http://portal.mec.gov.br/component/content/article/209-noticias/564834057/13381-pesquisarevela-empregabilidade-de-ex-alunos-da-rede-federal. Acesso em: 26 mar. 2019.

FRANCO, Maria Laura Puglisi Barbosa. Análise de conteúdo. 3. ed. Brasília: Liber Livro Editora, 2008.

FRIGOTTO, Gaudêncio; CIAVATTA, Maria; RAMOS, Marise. A gênese do Decreto n. 5154/2004: um debate no contexto controverso da democracia restrita. In: FRIGOTTO, G. et al. (Orgs.). Ensino médio integrado: concepções e contradições. São Paulo: Cortez, 2005. p. 21-56.

GIL, Antônio Carlos. Métodos e Técnicas de Pesquisa Social. 6. ed. São Paulo: Atlas, 2008. 
GOMES, Romeu. A análise e interpretação de dados de pesquisa qualitativa. In: MINAYO, Maria Cecília de Souza (Org.). Pesquisa social: teoria, método e criatividade. 30. ed. Petrópolis: Vozes, 2011. p. 79-108.

KUENZER, Acácia Zeneida. Da dualidade assumida à dualidade negada: O discurso da flexibilização justifica a inclusão excludente. Revista Educação \& Sociedade. Campinas, vol. 28, n. 100 - Especial, p. 1153-1178, out. 2007. Disponível em:

http://www.cedes.unicamp.br. Acesso em: 05 abr. 2019.

MANACORDA, Mario Alighiero. Marx e a Pedagogia Moderna. Tradução de Newton Ramos de Oliveira. Campinas SP: Editora Alínea, 2007.

MARX, Karl. O Capital: Crítica da economia política. Livro I: O processo de produção do capital. Tradução Rubens Enderle. São Paulo: Boitempo, 2013.

MINAYO, Maria Cecília de Souza. O desafio da pesquisa social. In: MINAYO, Maria Cecília de Souza (Org.). Pesquisa social: teoria, método e criatividade. 30. ed. Petrópolis: Vozes, 2011. p. 9-27.

MOURA, Dante Henrique. Educação básica e educação profissional e tecnológica: dualidade histórica e perspectiva de integração. Holos, Natal, v.2, p.4-30, 2007. Disponível em:

http://www2.ifrn.edu.br/ojs/index.php/HOLOS/article/viewFile/11/110. Acesso em: 25 mar. 2019.

MOURA, Dante Henrique; LIMA FILHO, Domingos Leite. A reforma do ensino médio: regressão de direitos sociais. Revista Retratos da Escola, Brasília, v. 11, n. 20, p. 109-129, jan./jun. 2017. Disponível em:

http://retratosdaescola.emnuvens.com.br/rde/article/view/760/pdf. Acesso em: 02 abr. 2019.

NOSELLA, Paolo. A Escola de Gramisci. 5. ed. Ampl. - São Paulo: Cortez, 2016.

NOSELLA, Paolo. Trabalho e perspectivas de formação dos trabalhadores: para além da formação politécnica. Revista Brasileira de Educação, v.12, n.34, p. 137-151, jan./abr. 2007. Disponívelem: http://www.scielo.br/pdf/rbedu/v12n34/a11v1234.pdf. Acesso em: 07 fev. 2019.

PACHECO, Eliezer. Institutos federais: uma revolução na educação profissional e tecnológica. In: PACHECO, Eliezer (Org.) Institutos Federais: uma revolução na educação profissional e tecnológica. Brasília, São Paulo: Editora Moderna, 2011. p. 13-32.

RAMOS, Marise Nogueira. História e Política da Educação Profissional. 1. ed. Curitiba: IFPR EAD, 2014. (Coleção Formação Pedagógica, v. 5)

ROMANELLI, Otaíza de Oliveira. História da Educação no Brasil. 8. ed. Petrópolis: Vozes, 1986.

SAVIANI, Dermeval. Trabalho e educação: fundamentos ontológicos e históricos. Revista Brasileira de Educação, Campinas, v.12, n.32, p. 52-180, jan./abr. 2007. Disponível em: http://www.scielo.br/pdf/rbedu/v12n34/a12v1234.pdf. Acesso em: 28 abr. 2019. 
Revista Prática Docente (RPD)

ISSN: 2526-2149

SEVERINO, Antônio Joaquim. Metodologia do Trabalho Científico. 23. ed. São Paulo: Cortez, 2007.

Recebido em: 24 de maio de 2019.

Aprovado em: 08 de setembro de 2019. 